\title{
İleri Derecede Kifoskolyotik Çocukta Lateral Pozisyonda Fiberoptik Entübasyon
}

\author{
Fiber-Optic Intubation of a Child with Advanced \\ Kyphoscoliosis in the Lateral Position
}

Özet

Kifoskolyoz, omurganın eğriliği ve rotasyonunun beraber görüldüğü, ciddi bir anatomik anormalliktir. Sendromların eşlik edebileceği kifoskolyoz, genel anestezi sırasında zor havayoluna neden olabilir. Bu yazıda, dental tedavi nedeniyle genel anestezi uygulanan ve supin pozisyon verilemeyecek kadar ileri derecede kifoskolyotik olan bir çocuk hastadaki zor havayolu yönetimi deneyimimizi sunmayı amaçladık.

Anahtar Kelimeler. fiberoptik entübasyon; lateral pozisyon; kifoskolyoz; çocuk

\section{Abstract}

Kyphoscoliosis is a serious anatomical abnormality in the form of lateral curvature and rotation of the spine. Kyphoscoliosis that may be accompanied by syndromes can also cause difficulty with airway management during general anesthesia. In this report, we aimed to present our experience of difficult airway management with a child patient who could not be put in the supine position due to advanced kyphoscoliosis and underwent general anesthesia for dental treatment.

Key Words: fiber-optic intubation; lateral position; kyphoscoliosis; child
Ahmet Selim Özkan, Sedat Akbaş, Zekine Begeç, Zeynep Köylü, Mahmut Durmuş

İnönü Üniversitesi, Anesteziyoloji ve Reanimasyon Anabilim Dalı, Malatya

Geliş Tarihi /Received : 25.02.2016 Kabul Tarihi /Accepted: 09.04.2016

Sorumlu Yazar/Corresponding Author Yrd. Doc. Dr. Ahmet Selim Özkan Turgut Özal Tıp Merkezi, Elazığ yolu 10. $\mathrm{km}$ Malatya

E-mail: asozkan61@yahoo.com 


\section{Giriş}

Kifoskolyoz (KS) gelişimsel vertebra bozukluklarının neden olduğu, spinal segmentin arkaya ve yanlara anormal açılandığı ciddi bir deformitedir (1). En yaygın görülen formu idiopatik olanıdır. Ancak, çeşitli nöromusküler hastalıklar sonucunda ikincil KS de görülebilir. Kifoskolyotik hastalarda tercih edilmesi gereken anestezi tekniği ile ilgili herhangi bir görüş birliği yoktur. Rejyonel ve genel anestezi teknikleri anestezistin tecrübesine göre tercih edilmektedir. Genel anestezi uygulamalarında, azalmış göğüs duvarı kompliyansı ve diyafram fonksiyonu, mevcut solunum sistemi problemlerinin daha da ağırlaşmasına neden olabilir (3). Bu durumlar ve görülebilecek entübasyon güçlügü de tercih edilecek anestezi yöntemini etkileyebilmektedir (2). Bu olgu sunumunda, dental girişim nedeniyle genel anestezi planlanan ve supin pozisyona getirilemeyecek kadar ağır KS'li bir çocuk hastanın zor havayolu yönetimindeki fiberoptik nazal entübasyon deneyimimizi sunmayı amaçladık.

\section{OLGU}

Çok sayıda diş çürüğü nedeniyle hastanemize başvuran 11 yaşındaki ve $25 \mathrm{~kg}$ ağırlığındaki erkek çocuk hastaya genel anestezi altında dental girişim planlandı. Preoperatif değerlendirmede hastada serebral palsi, hafif mental retardasyon, epilepsi ve ağır KS olduğu görüldü. Toraks ön-arka çapı artmış ve akciğer sesleri iki taraflı azalmıştı. Ağır KS nedeniyle supin pozisyon verilemeyen çocuğun boyun ekstansiyonu kısıtlı idi ve Mallampati skoru 3, tiromental mesafesi $5 \mathrm{~cm}$, sternomental mesafesi $11 \mathrm{~cm}$ olarak ölçüldü (Resim 1). Zor havayolu olabileceği öngörülerek videolarengoskop, fiberoptik bronkoskop, supraglottik havayolu cihazları, trakeostomi seti, farklı boyutlarda tüpler ve stileler hazırlandi. Altı saatlik açlık sonrası premedikasyon uygulanmayan hasta, tüm riskler yakınlarına anlatılarak ve ailesinden bilgilendirilmiş onam alınarak ameliyathaneye alındı. Rutin anestezi monitörizasyonu (EKG, nabız oksimetresi ve noninvaziv arteriyel tansiyon) uygulandi. Mental retardasyon nedeniyle hastaya uyanık entübasyon düşünülmedi. Supin pozisyon verilemeyen hastaya sağ lateral pozisyon verilerek maske ile ventilasyonun ve havayolu yönetiminin bu

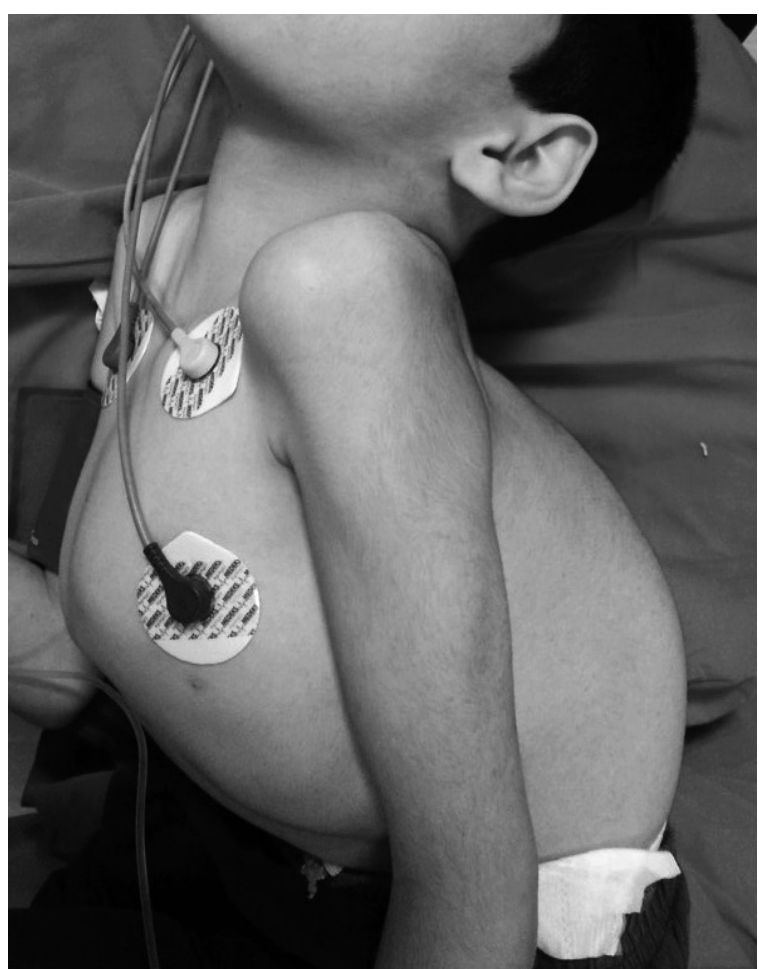

Resim 1. İleri kifoskolyoz nedenli pozisyon zorluğu ve lateral pozisyon.

pozisyonda sağlanması planlandı. Her iki burun deliğine \%2'lik lidokain $1 \mathrm{ml}$ ve $\% 0,05$ ksilometazolin sprey uyguland. Hasta $\% 100$ oksijen ile 5 dakika preoksijenize edildikten sonra anestezi indüksiyonu için $2 \mathrm{mg} / \mathrm{kg}$ propofol, 1 mikrogram $/ \mathrm{kg}$ fentanil ve maske ventilasyonu sağlandığ 1 görülünce $2 \mathrm{mg} / \mathrm{kg}$ süksinilkolin uygulandı. Spiralli tüp sıcak su ile isıtılarak yumuşatıldı ve lidokain jel ile kayganlaştırıldı. Fiberoptik bronkoskop (FOB) (Olympus LF-DP; Tokyo, Japonya) üzerine spiralli tüp yerleştirildi ve daha etkin olduğu düşünülen sağ burun deliğine deneyimli anestezist tarafindan FOB ile girildi. FOB uygulaması sırasında yardımcı anestezist jaw-thrust manevrasıyla ve başa hafif ekstansiyon vererek nazofarengeal pasajın açılmasını ve görüntünün iyileşmesini sağladı. Glottis net olarak görüldükten sonra FOB ile vokal kordlar arasından geçildi ve 4,5 numara spiralli tüp FOB üzerinden kaydırılarak hasta nazotrakeal entübe edildi. Endotrakeal tüpün ucunun glottisin $4 \mathrm{~cm}$ altında olduğu FOB ile doğrulandı ve her iki akciğerin eşit havalandığı görüldü. Anestezi idamesi, \%2 sevofluran, \%50 oksijen / \%50 azot protoksit ile sağlandı. Operasyon boyunca hemodinami stabil seyretti. Dental girişim 
de sağ lateral pozisyonda yapıldı. Postoperatif analjezi için parasetamol uygulandı. Operasyon 45 dakika sürdü ve operasyon sonunda hasta sorunsuz bir şekilde ekstübe edildi ve postoperatif takip ünitesinde sorun yaşanmayan hasta servise gönderildi.

\section{TARTIŞMA}

Kifoskolyoz (KS) vertebradaki öne-arkaya açlanma ve laterale yönelme olarak tanımlanır ve prevalans1 \%0,3-15,3 arasındadır (2). Bu hastalarda, akciğer problemlerine ek olarak havayolu zorlukları ile de sık karşılaşılır. Vertebradaki anatomik deformiteler, anestezi yönetiminde ciddi sorunlara yol açabilir, bu nedenle anestezi yönetimini önemli kılar (4). Anestezi öncesi değerlendirmede havayolunun dikkatle muayene edilmesi, zor havayolu beklenen hastaların entübasyonu için altın standart yöntemdir (5). Havayolu anomalilerine bağlı zor havayolu beklenen hastalarda, postür bozukluklarının da gelişmesi anestezi yönetiminde ek sorunlara neden olabilir.

Bizim olgumuzda, ileri KS nedeniyle supin pozisyon verilemeyen ve anatomik deformiteleri nedeniyle zor havayolu olabileceği düşünülen hastaya, genel anestezi altında lateral pozisyonda fiberoptik nazal entübasyon uygulanmasına karar verildi. KS nedeniyle zor havayolu beklenen hastalarda genel anesteziye alternatif olarak rejyonel anestezi de uygulanabilir. Genel anestezi gerekli ise, malign hipertermi gelişme riski nedeniyle, kas gevşetici uygulamadan entübasyon veya uyanık entübasyon denenmelidir. Bizim olgumuzda ağız içine müdahale edileceğinden ve kooperasyon sorunu yaşandığından hastaya genel anestezi uygulanmak zorunda kalındı. Hastanın uyanık entübasyon için uygun olmaması nedeniyle zor havayolu algoritmasına uygun olarak gerekli hazırlıklar yapılıp lateral pozisyonda fiberoptik nazal entübasyon uygulanmasina karar verildi. Ayrıca entübasyon lateral pozisyonda olacağından kas gevşetici uygulamak zorunda kalındı. Oral kavite cerrahilerinde oral yola göre nazal yol tercih edilmektedir (6). Bu nedenle bizim olgumuzda da nazal entübasyon uyguland..

KS'li hastalarda uzamış ve tekrarlayan entübasyon girişimleri morbiditenin artmasına neden olmaktadır (7). Bu nedenle entübasyon girişimlerinin deneyimli anestezistler tarafindan seri olarak uygulanması morbiditenin azalmasına yardımcı olacaktır. Bu hastalarda fiberoptik bronkoskop ile alternatif olarak direkt laringoskopi veya videolaringoskop ile nazal entübasyon tercih edilebilir.

Genel anestezi uygulanan KS'li hastalarda entübasyon kadar ekstübasyon da önem arz eder. Bu hastaların reentübe edilebileceği akılda tutulmalı, özellikle zor entübe edilmiş olgularda bir plan dahilinde ekstübasyon denenmeli ve hasta transfer oluncaya kadar acil havayolu ekipmanlarının hazır bulundurulması sağlanmalıdır. Gerekli ise ekstübasyonu kolaylaştıracak exchange kateterler kullanılabilir (8).

\section{SONUÇ}

Pozisyonel değişiklikleri ve anatomik anormallikleri nedeniyle ağır KS’li hastalarda zor havayolu ile sık karşılaşılır. KS’li hastalarda hangi anestezi tekniğinin uygulanması gerektiği hakkında herhangi bir görüş birliği yoktur. Lateral pozisyonda fiberoptik nazal entübasyon, supin pozisyon verilemeyen bu tip çocuklarda havayolu kontrolü için alternatif bir yöntem olarak uygulanabilir.

\section{KAYNAKLAR}

1. McMaster MJ, Glasby MA, Singh H, Cunningham S. Lung function in congenital kyphosis and kyphoscoliosis. J Spinal Disord Tech. 2007;20(3):203-8.

2. Veliath DG, Sharma R, Ranjan R, Kumar CR, Ramachandran T. Parturient with kyphoscoliosis (operated) for cesarean section. J Anaesthesiol Clin Pharmacol. 2012;28(1):124-6.

3. Moran DH, Johnson MD. Continuous spinal anesthesia with combined hyperbaric and isobaric bupivacaine in a patient with scoliosis. Anesth Analg. 1990;70(4):445-7.

4. Benumof JL. The ASA Management of the of the difficult airway algorithm and explanation-analysis of the algorithm. In: Benumof JL (ed.), Airway Management: Principles and Practice. St. Louis: Mosby-Year Book; 1996;150.

5. Batra YK, Mathew P. Airway management with endotracheal intubation (including awake intubation and blind intubation. Indian J Anaesth. 2005;49(4):263-8.

6. De Hert S, Imberger G, Carlisle J, Diemunsch P, Fritsch G, Moppett I, et al. Preoperative evaluation of the adult patient undergoing non-cardiac surgery: guidelines 
from the European Society of Anaesthesiology. Eur J Anaesthesiol. 2011;28(10):684-722.

7. Saracoglu KT, Eti Z, Kavas AD, Umuroglu T. Straight video blades are advantageous than curved blades in simulated pediatric difficult intubation. Paediatr Anaesth. 2014;24(3):297-302.
8. Law JA, Broemling N, Cooper RM, Drolet P, Duggan LV, Griesdale DE, et al. The difficult airway with recommendations for management--part 2--the anticipated difficult airway. Can J Anaesth. 2013;60(11):1119-38. 